\title{
Optimization of type 2 diabetes mellitus control in Egyptian patients
}

\section{ABSTRACT}

Background. Optimum management for a patient with type 2 diabetes mellitus (T2DM) requires periodic evaluation and monitoring of the patient's risk factors to measure its impact on different classes of treatment. Also the diabetes complications must be evaluated and initial review of drug history. This study aims to analyze clinical characteristics, risk factors, and contributions of each variable on predictive performances of each protocol used in the treatment of T2DM patients.

Methods. A comparative description, a study of 2000 Egyptian patients. Patients were categorized into eight groups according to the treatment protocol used. Multivariate logistic regression was applied to assess the probability of each protocol to reach target glycated hemoglobin $\mathrm{A}_{1 \mathrm{c}}\left(\mathrm{HbA}_{1 \mathrm{c}}\right)$ in comparison to the standard protocol metformin + SU (protocol A)

Results. The proportion of patients in our study reaching $\mathrm{HbA}_{1 \mathrm{c}} \leq 7 \%$ ranged between $48.9 \%$ in dipeptidyl peptidase-4 inhibitors (DPP-4 inhibitors) group (protocol $\mathrm{H}$ ), and $59.2 \%$ in metformin + DPP-4 inhibitors group (protocol B). In subgroup analysis according to disease duration ( $\leq 8$ years duration), mean $\mathrm{HbA}_{1 \mathrm{c}}$ spanned from $7.4 \pm 0.49 \%$ in SU monotherapy (protocol D) to $8.6 \pm 0.5 \%$ in metformin + SU; the likelihood of reaching $\mathrm{HbA}_{1 \mathrm{c}}>7$ was lower in the protocol $A$ and protocol B.

Conclusion. Patients not controlled on metformin alone with lifestyle modification should be switched to either

Address for correspondence:

Mohammed Ahmed Mobarez

Gamalia Street 14, Cairo, Egypt

e-mail: mobarezmohamed@yahoo.com

Clinical Diabetology 2020, 9; 6: 433-441

DOI: $10.5603 /$ DK.2020.0059

Received: 25.08 .2020

Accepted: 03.11.2020 protocol A or protocol B based on the preferential clinical outcome if there is no contraindication, as these two protocols are associated with the best result and a high percentage of patients reaching target $\mathrm{HbA}_{1 \mathrm{c}}$. (Clin Diabetol 2020; 9; 6: 433-441)

Key words: type 2 diabetes, $\mathrm{HbA}_{1 c^{\prime}}$ metformin, likelihood, clinical characteristics, multivariate analysis

\section{Introduction}

Type 2 diabetes mellitus (T2DM) is considered one of the major worldwide public health problems. It is mainly a consequence of the currently observed bad lifestyle behavior such as sedentary life, fast food and obesity, which is considered an essential contributor to T2DM worldwide [1]. By 2030, it is expected that around half of the adult population in the world will be overweight (BMI $25-29.9 \mathrm{~kg} / \mathrm{m}^{2}$ ) or obese (BMI $>30 \mathrm{~kg} / \mathrm{m}^{2}$ ) [2]. Thus, diabetes prevalence is predicted to rise to 693 million worldwide by 2045 [3]. T2DM is associated with a large number of complications and increased mortality $[4,5]$, as it is the main cause of renal failure [6-8], blindness, and leg amputations [9]. Also, diabetes mellitus has of cardiovascular complications, the major cause of death in patients with diabetes [10]. So, patient quality of life reduces significantly with this disease, especially if uncontrolled, and life expectancy is decreased by, on average, eight years compared with healthy people [3].

The American Diabetes Association's Standards of Medical Care in Diabetes [11] focuses on diet and other non-pharmacological measures for the management of T2DM, but the concept of these measures is not applicable in many of primary health care systems $[12,13]$. Optimum management for a patient with diabetes requires an initial evaluation of the patient's 
risk factors for careful selection of different classes of treatment. Additionally, diabetes complications, as well as medical history should be evaluated [14]. So far metformin is the first-line treatment for T2DM unless there are contraindications, either metformin alone or with lifestyle modifications or in combination with other agents [15]. In comparison with sulfonylureas (SUs), metformin as firstline therapy has a good impact on target $\mathrm{HbA}_{1 \mathrm{c}^{\prime}}$ weight, and cardiovascular mortality [16]. However, choosing a second-line therapy is challenging, because it differs according to patient characteristics and risk factors.

A lot of studies suggests that each new class of treatment if added to metformin generally lowers $\mathrm{HbA}_{1 \mathrm{c}}$ by approximately $0.7-1.0 \%$ [17]. If the $\mathrm{HbA}_{1 \mathrm{c}}$ target is not achieved after approximately 3 months, a combination of metformin and any one of the preferred six treatment options should be considered: SU, thiazolidinedione, dipeptidyl peptidase 4 (DPP-4) inhibitor, sodium glucose cotransporter 2 (SGLT2) inhibitor, glucagon like peptide (GLP-1) receptor agonist, or basal insulin; the choice of agent to add is based mainly on the drug effects, side effects and patient factors. Nowadays, the choice of a second agent to add to metformin is controversial. Rather, drug choice is based on avoidance of side effects, particularly risk of hypoglycemia and weight gain, cost, and patient preference [18].

A study including 2677 adult American patients with self-reported T2DM called National Health and Nutrition Examination Survey showed that mean $\mathrm{HbA}_{1 c}$ was reduced with treatment with different classes, but still didn't reach the recommended treatment target [19]. Additionally, the actual effectiveness in clinical practice is mostly unknown.

\section{Aim of the study}

Our study was designed to identify clinical characteristics, risk factors affecting target goal control and likelihood of each protocol to achieve target $\mathrm{HbA}_{1 \mathrm{c}}$ in unselected T2DM patients.

\section{Methods}

A comparative descriptive, observational study. Representative sample of adult T2DM patients who received treatment at several diabetes outpatient clinics were assessed to evaluate different treatments' effects on $\mathrm{HbA}_{1 c^{\prime}}$ the relationship between different treatments and patient characteristics, risk factors and proportion of diabetes complication in outpatient clinics of the following hospitals (Ahmed Maher Hospital, National Diabetes Center, Alasr Elainy Hospital, Eldemerdash Hospital and Elsalam Hospital) in the period from January 2017 to February 2019.
Patients received metformin (Glucophage, 500 and $850 \mathrm{mg}$ tablets, Bristol Myers Squibb, NY) as monotherapy (protocol C). During the 4-week run-in period, patients were treated with 500 to $2550 \mathrm{mg} /$ day of metformin divided into one to three doses. The dose was adjusted during the first 3 weeks of the run-in to (1) achieve and maintain target fasting blood glucose (FBG) levels of $90-126 \mathrm{mg} / \mathrm{dL}$, or (2) the maximally tolerated dose, or (3) a maximum daily dose of $2550 \mathrm{mg}$. The patient's metformin dose was not changed after the fourth week of the run-in period, unless a dose reduction was necessary for clinical reasons. At the end of the run-in period, patients who were not able to achieve the FBG target of 90-126 $\mathrm{mg} / \mathrm{dL}$ on metformin only were randomized to one of four treatment regimens: (1) metformin and biphasic insulin aspart (protocol E) (70\% protaminated insulin aspart, 30\% soluble insulin aspart, NovoLog Mix 70/30) administered within 10 min before the start of dinner; (2) metformin and Glibenclamide $10 \mathrm{mg}$ twice daily (protocol A) or (3) metformin and sitagliptin (protocol B) $100 \mathrm{mg}$ daily dose or (4) metformin + SU + insulin NPH (protocol F). The dose adjustments were based on twice-weekly selfmonitored blood glucose (SMBG) assessments. SU monotherapy (Glibenclamide) $10 \mathrm{mg}$ twice daily (protocol D). DPP-4 inhibitors monotherapy (sitagliptin) $100 \mathrm{mg}$ daily dose (protocol H). SU (Glibenclamide $10 \mathrm{mg}$ twice daily) + insulin NPH (protocol G). The starting insulin dose was $0.16 \mathrm{U} / \mathrm{kg}$. During the first 4 weeks of treatment, the insulin dosage was adjusted by 2-6 $\mathrm{U}$ to achieve FBG levels of $90-126 \mathrm{mg} / \mathrm{dL}$.

For all subjects in groups, patient education programs, and counseling with oral and printed material about types of food suitable for type 2 diabetes, lifestyle modifications, any potential dietary factors that may be harmful to patients, and the importance of adherence to medication and home self-measurement.

A total of 2000 Egyptian patients, who were categorized into eight groups according to the protocol used, were recruited.

Patient data collection included standardized medical examinations, patient interviews, blood sample collection and medical history review. We analyzed age, sex, diabetes duration (DD), $\mathrm{HbA}_{1 \mathrm{c}^{\prime}}$ low-density lipoprotein (LDL), lipid-lowering medication (LW), systolic and diastolic blood pressure (BP), antihypertensive medication, estimated glomerular filtration rate (eGFR), cumulative microalbuminuria, body mass index (BMI), smoking, physical activity (PA), and a history of cardiovascular disease (CVD) for each protocol group.

We used cut-off $\leq 7 \%$ instead of $<7 \%$ as $\mathrm{HbA}_{1 c}$ goal in Egyptian outpatient clinics standard, since to most clinicians, $7 \%$ is the treatment goal (according to hospitals protocols). A smoker was defined as 
smoking one or more cigarettes per day, or who had stopped smoking within the past 3 months. Estimated GFR was calculated using the Modification of Diet in Renal Disease (MDRD) equation: $175 \times$ serum creatinine/88.4 $1.154 \times$ age -0.203 for men, and: $175 \times$ serum creatinine/88.4-1.154 $\times$ age- $0.203 \times 0.742$ for women [20]. Cumulative microalbuminuria was defined as urine albumin excretion $>20 \mathrm{mcg} / \mathrm{min}$ in two of three consecutive tests. History of CVD and CHD was defined as history of at least one CVD or CHD. Physical activity was defined according to the Center for Disease Control and Prevention (CDC): moderate physical activity - walking at a moderate or brisk pace of 3 to $4.5 \mathrm{mph}$ on a level surface inside or outside; mild - walking at a pace of less than 3 to $4.5 \mathrm{mph}$; severe - race-walking and aerobic walking at a pace of 5 mph or faster [21]. The definition of T2DM used in this study was a patient treated with oral hypoglycemic agents (OHAs) only, or onset age of diabetes at the age of $\geq 40$ years and treated with insulin combined with oral hypoglycemic agent. To ensure at least six months of continuous medication, enrolled were only patients treated in Egypt outpatient clinics who had filled at least six-monthly prescriptions.. One prescription generally corresponds to one-month continuous treatment. Thus, six filled prescriptions correspond to at least six months of medication.

\section{Statistical analysis}

Continuous variables are expressed as mean \pm standard deviation (SD) and ranges, and as medians when the data were nonparametric. Comparisons between two parallel groups with continuous data were performed using an independent $t$ test, while similar non-parametric categorical data were compared using the chi-square test and non-parametric continuous data were compared using the Mann Whitney test. Univariate and multivariate analyses were used to predict influence of clinical characteristics and protocol type on the likelihood of reaching $\mathrm{HbA}_{1 \mathrm{c}}>7.0 \%$ using metformin and $\mathrm{SU}$ as a reference. The confidence interval was set at $95 \%$. Thus, the $P$ value was considered significant at $P<0.05$. Statistical analyses were conducted using the Statistical Package for the Social Sciences (IBM SPSS ${ }^{\circledR}$ 25), and R program software version 9.2.

\section{Results}

\section{Treatment regimens}

Of the 2000 patients treated with the most common prescribed treatment, $9.8 \%$ were treated with metformin monotherapy (protocol C), 9.2\% SU monotherapy (protocol D), $25.7 \%$ metformin + SU (protocol A), $14.2 \%$ metformin + DPP-4 inhibitors (protocol B),
$10.6 \%$ metformin + insulin NPH (protocol E), 10.5\% metformin + SU + insulin NPH (protocol F), 11.3\% $\mathrm{SU}+$ insulin NPH (protocol G), 8.7\% DPP-4 inhibitors monotherapy (protocol $\mathrm{H}$ ).

\section{Clinical characteristics}

Age varied between $53.1 \pm 7.1$ and $57.2 \pm 6.3$ years in the treatment groups; diabetes duration 7.2 $\pm 2.1-10.3 \pm 2.1$ years; BMI $26.9 \pm 3.9-30.3 \pm 5.8$ $\mathrm{kg} / \mathrm{m}^{2}$; eGFR $52.1 \pm 7.01-55.1 \pm 9.3 \mathrm{ml} / \mathrm{min} / 1.73 \mathrm{~m}^{2}$; proportion with cumulative microalbuminuria $23-33 \%$; history of CVD $24.3-28.8 \%$ (Table 1). Patients on metformin + SU had the highest duration of diabetes, baseline $\mathrm{HbA}_{1 \mathrm{c}}$ and proportion of smokers; patients on metformin monotherapy had a shorter duration of diabetes, a lower proportion of patients with microalbuminuria, and a lower proportion of patients with CVD than the other protocols. Patients on metformin + SU + insulin NPH were older, had higher eGFR, and more frequent antihypertensive treatment; there were a higher proportion of women on all treatments.

\section{Treatment results}

Comparing glycated hemoglobin $A_{1 c}\left(\mathrm{HbA}_{1 c}\right)$ between the groups, there were significant differences, as it ranged from $7.6 \pm 0.49$ in metformin $+\mathrm{SU}+$ insulin $\mathrm{NPH}$ (lowest) to $8.6 \pm 5.3 \%$ in metformin + SU (highest), $\mathrm{P}<0.0001$. The proportion of patients reaching $\mathrm{HbA}_{1 \mathrm{c}} \leq 7 \%$ ranged between $48.9 \%$ in DPP-4 inhibitors monotherapy, and $59.2 \%$ in metformin + DPP-4 inhibitors. In a subgroup of newly diagnosed patients ( $\leq 8$ years duration), mean $\mathrm{HbA}_{1 \mathrm{c}}$ spanned from $7.4 \pm$ $0.49 \%$ in SU monotherapy, to $8.6 \pm 0.5$ in metformin + $\mathrm{SU}$. Patient with diabetes duration $>8$ years has $\mathrm{HbA}_{1 \mathrm{c}}$ range from $7.57 \pm 0.51 \mathrm{SU}$ monotherapy to $8.65 \pm$ 0.53 in metformin + SU (Table 2).

The percent of patients reaching targets for blood pressure and LDL ranged between $41.2 \%$ to $49.3 \%$ and $23.5 \%$ to $36.1 \%$, respectively (Table 2 ). Comparisons between men and women (Table 3 ) showed significant differences in the odds of obtaining $\mathrm{HbA}_{1 \mathrm{c}} \leq 7$ in only two treatment groups (protocol $A$ and $B$ ). There were slightly higher proportions of men among those who reached $\mathrm{HbA}_{1 \mathrm{c}} \leq 7 \%$ in all treatment groups. Differential impact of different variables on the likelihood of having $\mathrm{HbA}_{1 \mathrm{c}}$ such as age, sex, use of lipid-lowering agents (lowest impact), physical activity, disease duration, body mass index, and estimated glomerular filtration rate (highest impact) is presented in Figures 1 and 2 .

Data in Table 4 and Figure 3 give the likelihood of having $\mathrm{HbA}_{1 \mathrm{c}}>7 \%$ in each group and the impact of each variable compared to patients on metformin + SU (reference). Patients on all other pharmacological 
Table 1. Clinical characteristics of T2DM patients on most commonly prescribed treatment, 2017

\begin{tabular}{|c|c|c|c|c|c|c|c|c|c|}
\hline Protocol & & $\begin{array}{c}A \\
n=514\end{array}$ & $\begin{array}{c}\text { B } \\
n=284\end{array}$ & $\begin{array}{c}C \\
n=196\end{array}$ & $\begin{array}{c}D \\
n=184\end{array}$ & $\begin{array}{c}E \\
n=211\end{array}$ & $\begin{array}{c}F \\
n=211\end{array}$ & $\begin{array}{c}\text { G } \\
n=226\end{array}$ & $\begin{array}{c}H \\
n=174\end{array}$ \\
\hline Age (years) & Mean \pm SD & $54.53 \pm 6.9$ & $54.51 \pm 6.8$ & $55.7 \pm 6.5$ & $55.3 \pm 7.1$ & $53.5 \pm 7.2$ & $56.1 \pm 7.5$ & $53.1 \pm 7.1$ & $57.2 \pm 6.3$ \\
\hline Gender & $\%$ & $40.7 / 59.3$ & $39.1 / 60.9$ & $34.2 / 65.8$ & $42.4 / 57.6$ & $40.8 / 59.2$ & $31.8 / 68.2$ & $43.4 / 56.6$ & $36.2 / 63.8$ \\
\hline \multicolumn{10}{|l|}{ Male/female } \\
\hline Diabetes duration & Mean \pm SD & $10.3 \pm 2.1$ & $8.7 \pm 2.0$ & $7.2 \pm 2.1$ & $7.6 \pm 1.9$ & $7.5 \pm 2.7$ & $7.3 \pm 1.8$ & $7.5 \pm 2.4$ & $7.5 \pm 2.0$ \\
\hline Smokers & $\%$ & 24.7 & 21.8 & 23 & 17.9 & 20.4 & 16.8 & 16 & 22.5 \\
\hline BMI $\left[\mathrm{kg} / \mathrm{m}^{2}\right]$ & Mean \pm SD & $27.9 \pm 5.1$ & $28.3 \pm 4.9$ & $28.8 \pm 4.4$ & $26.9 \pm 3.89$ & $30.3 \pm 5.8$ & $28.8 \pm 5.4$ & $28.2 \pm 4.7$ & $29.1 \pm 5.1$ \\
\hline $\mathrm{HbA}_{1 \mathrm{c}}[\mathrm{mmol} / \mathrm{mol}]$ & Mean \pm SD & $9.27 \pm 0.18$ & $8.6 \pm .17$ & $7.8 \pm .15$ & $7.9 \pm 0.53$ & $7.6 \pm 0.2$ & $7.8 \pm 0.19$ & $8.2 \pm 0.18$ & $8.1 \pm 0.17$ \\
\hline $\mathrm{BP}[\mathrm{mm} \mathrm{Hg}]$ & $\%$ & 43 & 37.7 & 35 & 44 & 46 & 42 & 40 & 42.5 \\
\hline $\begin{array}{l}\text { Use of lipid-lower- } \\
\text { ing agents }\end{array}$ & $\%$ & 57.8 & 63.7 & 61.2 & 58.2 & 62 & 60.2 & 46.9 & 56.5 \\
\hline eGFR & Mean \pm SD & $52.6 \pm 7.7$ & $53.3 \pm 8.1$ & $53.5 \pm 7.3$ & $52.8 \pm 7.91$ & $55.1 \pm 9.33$ & $53.4 \pm 8.7$ & $52.1 \pm 7.01$ & $54.2 \pm 6.88$ \\
\hline Microalbuminuria & $\%$ & 30 & 23 & 26 & 32 & 28 & 29.9 & 33 & 27 \\
\hline History of CVD & $\%$ & 28.8 & 26.1 & 25.5 & 25 & 28 & 28.4 & 24.3 & 26.4 \\
\hline $\begin{array}{l}\text { Physical activity } \\
\text { (low) }\end{array}$ & $\%$ & 49.6 & 49 & 53 & 43.5 & 27.5 & 49.3 & 50 & 47.1 \\
\hline $\begin{array}{l}\text { Physical activity } \\
\text { (moderate) }\end{array}$ & $\%$ & 29.6 & 29.9 & 27 & 32.6 & 27.5 & 32.7 & 30.5 & 29.9 \\
\hline $\begin{array}{l}\text { Physical activity } \\
\text { (high) }\end{array}$ & $\%$ & 20.8 & 21 & 19 & 23.9 & 27.5 & 18 & 19.5 & 23 \\
\hline $\begin{array}{l}\text { Vaccinated with } \\
\text { influenza/pnemo- } \\
\text { coccal }\end{array}$ & $\%$ & $4.5 / 4.5$ & $4.2 / 3.2$ & $2.6 / 2.6$ & $6.5 / 6$ & $5.7 / 5.3$ & $3.3 / 3.3$ & $4 / 4$ & $3.4 / 3.4$ \\
\hline
\end{tabular}

Means \pm standard deviation (Mean $\pm \mathrm{SD}$ ) and proportions (\%); $\mathrm{BMI}$ - body mass index; $\mathrm{HbA}_{1 \mathrm{c}}$ - hemoglobin $\mathrm{A}_{1 \mathrm{c}}$; $\mathrm{BP}-$ blood pressure; eGFR — estimated glomerular filtration rate; CVD - cardiovascular disease; T2DM - type 2 diabetes mellitus

Table 2. Risk factor control

\begin{tabular}{|c|c|c|c|c|c|c|c|c|c|}
\hline & & $\begin{array}{c}A \\
n=514\end{array}$ & $\begin{array}{c}B \\
n=284\end{array}$ & $\begin{array}{c}C \\
n=196\end{array}$ & $\begin{array}{c}D \\
n=184\end{array}$ & $\begin{array}{c}E \\
n=211\end{array}$ & $\begin{array}{c}F \\
n=211\end{array}$ & $\begin{array}{c}G \\
\mathrm{n}=226\end{array}$ & $\begin{array}{c}H \\
n=174\end{array}$ \\
\hline $\mathrm{HbA}_{1 \mathrm{c}}$ & Mean \pm SD & $8.6 \pm 0.53$ & $8.2 \pm 0.51$ & $7.5 \pm 0.6$ & $7.6 \pm 0.52$ & $7.7 \pm 0.61$ & $7.6 \pm 0.49$ & $7.7 \pm 0.51$ & $7.7 \pm 0.55$ \\
\hline $\mathrm{HbA}_{1 \mathrm{c}} \leq 7$ & $\%$ & 56.6 & 59.2 & 51.5 & 50 & 53.6 & 57.3 & 51.8 & 48.9 \\
\hline $\begin{array}{l}\mathrm{HbA}_{1 \mathrm{c}} \text { for diabetes } \\
\text { duration ( }>8 \text { years) }\end{array}$ & Mean \pm SD & $\begin{array}{c}8.65 \pm \\
0 . .53\end{array}$ & $8.31 \pm 0.54$ & $7.61 \pm 0.5$ & $7.57 \pm .51$ & $7.64 \pm 0.51$ & $7.7 \pm 0.53$ & $7.6 \pm .52$ & $7.8 \pm 0.46$ \\
\hline $\begin{array}{l}\mathrm{HbA}_{1 \mathrm{c}} \text { for diabetes } \\
\text { duration ( } \leq 8 \text { years) }\end{array}$ & Mean \pm SD & $8.6 \pm 0.5$ & $8.2 \pm .52$ & $7.6 \pm .53$ & $7.4 \pm 0.4$ & $7.6 \pm 0.53$ & $7.5 \pm 0.54$ & $7.7 \pm 0.5$ & $7.6 \pm 0.55$ \\
\hline Diastolic & Mean \pm SD & $82.3 \pm 8.8$ & $81.1 \pm 8.9$ & $81.5 \pm 9.3$ & $82 \pm 9.2$ & $81.5 \pm 9.5$ & $80.1 \pm 9.1$ & $82 \pm 9.6$ & $81 \pm 8.7$ \\
\hline Systolic & Mean \pm SD & $\begin{array}{c}132.5 \pm \\
14.2\end{array}$ & $\begin{array}{c}130.6 \pm \\
14.5\end{array}$ & $131.1 \pm 15$ & $132 \pm 14.7$ & $131 \pm 15$ & $132 \pm 14.8$ & $131 \pm 15.5$ & $\begin{array}{c}132.7 \pm \\
13.8\end{array}$ \\
\hline$B P<130 / 80$ & $\%$ & 44 & 45.4 & 44.9 & 44.6 & 47.9 & 49.3 & 41.2 & 45 \\
\hline LDL & Mean \pm SD & $118.5 \pm 25$ & $117 \pm 24$ & $120 \pm 25$ & $121 \pm 25.6$ & $119 \pm 23.6$ & $120.6 \pm 24$ & $\begin{array}{c}118.7 \pm \\
25.3\end{array}$ & $119.5 \pm 26$ \\
\hline $\mathrm{LDL}<100$ & $\%$ & 26.8 & 27.8 & 23.5 & 27.7 & 23.7 & 36.1 & 28.3 & 27 \\
\hline HDL & Mean \pm SD & $35 \pm 5.6$ & $34.8 \pm 5.2$ & $34 \pm 6.1$ & $36.1 \pm 5.7$ & $35 \pm 5.4$ & $36 \pm 6$ & $35.5 \pm 5.3$ & $35 \pm 5.3$ \\
\hline
\end{tabular}

$\mathrm{HbA}_{1 c}$ - hemoglobin $\mathrm{A}_{1 c^{i}}$ LDL — low-density lipoprotein; $\mathrm{HDL}$ - high-density lipoprotein 
Table 3. Glycemic control in men and women

\begin{tabular}{|c|c|c|c|c|c|c|c|c|c|}
\hline & & $\begin{array}{c}\text { A } \\
n=514\end{array}$ & $\begin{array}{c}\text { B } \\
n=284\end{array}$ & $\begin{array}{c}C \\
n=196\end{array}$ & $\begin{array}{c}D \\
n=184\end{array}$ & $\begin{array}{c}E \\
n=211\end{array}$ & $\begin{array}{c}F \\
n=211\end{array}$ & $\begin{array}{c}G \\
n=226\end{array}$ & $\begin{array}{c}H \\
n=174\end{array}$ \\
\hline \multirow[t]{3}{*}{$\mathrm{HbA}_{1 \mathrm{c}}$ mean $\mathrm{M}$} & $\mathrm{n}$ & 209 & 111 & 67 & 78 & 86 & 67 & 98 & 63 \\
\hline & Mean $\pm S D$ & $8.66 \pm 0.53$ & $8.2 \pm 0.6$ & $7.7 \pm 0.51$ & $7.6 \pm 0.52$ & $7.6 \pm 0.54$ & $7.7 \pm 0.53$ & $7.7 \pm 0.52$ & $7.6 \pm 0.51$ \\
\hline & $\mathrm{n}$ & 305 & 173 & 129 & 106 & 125 & 144 & 128 & 111 \\
\hline $\mathrm{HbA}_{1 \mathrm{c}}$ mean $\mathrm{W}$ & Mean $\pm S D$ & $8.63 \pm 0.5$ & $8.4 \pm 0.52$ & $7.6 \pm 0.53$ & $7.7 \pm 0.53$ & $7.6 \pm 0.53$ & $7.5 \pm 0.53$ & $7.85 \pm 0.6$ & $7.7 \pm 0.5$ \\
\hline P value* & & 0.539 & 0.033 & 0.143 & 0.662 & 0.834 & 0.664 & 0.727 & 0.707 \\
\hline $\mathrm{HbA}_{1 \mathrm{c}} \leq 7 \mathrm{M}$ & $\%$ & 63 & 67 & 53 & 56 & 60 & 58 & 52 & 57 \\
\hline $\mathrm{HbA}_{1 \mathrm{c}} \leq 7 \mathrm{~W}$ & $\%$ & 52 & 54 & 50 & 45 & 49 & 57 & 51.5 & 44 \\
\hline$P$ value* & & 0.008 & 0.026 & 0.385 & 0.090 & 0.063 & 0.492 & 0.525 & 0.068 \\
\hline
\end{tabular}

*P value of categorical data were performed using the chi-square test; $\mathrm{M}-$ men; $\mathrm{W}-$ women

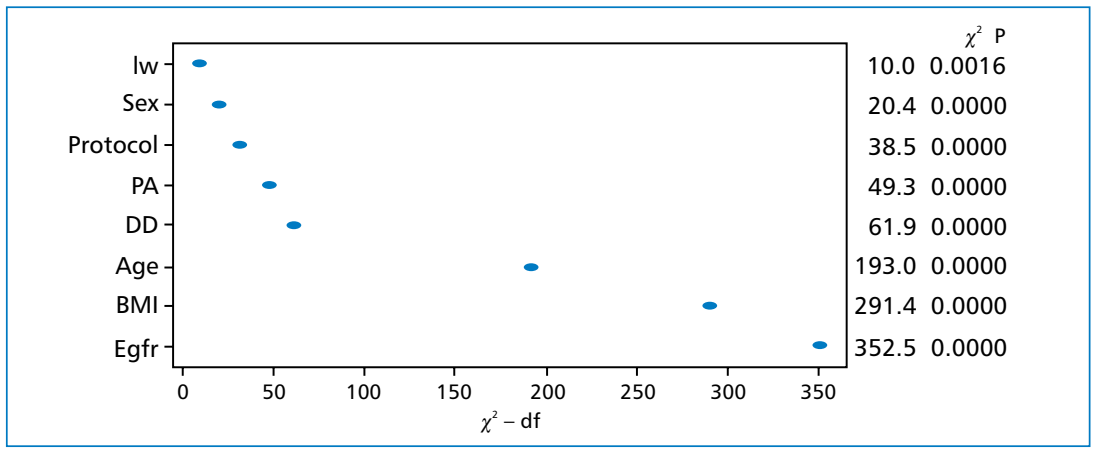

Figure 1. Contribution of each individual variable on predictive performance of the final multivariate model. Lw - lipid-lowering medication; PA — physical activity; DD — disease duration; BMI — body mass index; eGFR — estimated glomerular filtration rate

treatment regimens had a significantly higher likelihood of having $\mathrm{HbA}_{1 \mathrm{c}}>7 \%$, ranging from) OR 2.89; $95 \% \mathrm{Cl}$ 1.41-5.92 (in metformin + SU + insulin NPH group to (OR 5.22; 95\% Cl 2.58-10.56( in DPP-4 inhibitors group, except for patients on metformin + DPP-4 inhibitors (OR 1.71; 95\% Cl 0.94-3.12) where the difference versus metformin + SU regimen was insignificant. Patients on metformin + DPP-4 inhibitors, in general, had the lowest likelihood of having $\mathrm{HbA}_{1 \mathrm{c}}>7 \%$. Patients on SU monotherapy and DPP-4 inhibitors monotherapy had the lowest likelihood of reaching the target $\mathrm{HbA}_{1 \mathrm{c}}$ $\leq 7$. The agreement between predicted data with real observation data is demonstrated in figure 3 , indicating the internal validity of the developed regression model. Moreover, area under ROC curve was significantly higher $(P<0.0001)$, confirming the internal validity.

Table 5 shows that our model had good predictability and there is high concordance $(0.96)$ between observed and predicted data.

\section{Discussion}

The results of the present study proved that outpatient clinics in Egypt apply world treatment guidelines in routine clinical care, as high percent of patients with T2DM (70.8\%) were treated with metformin alone or in combination with other agents [22].

Fewer studies describing different treatment protocols according to different patient characteristics in real practice in Egypt are available, but there are many studies evaluating treatment effects of different T2DM medications. This study is a nation-wide cross sectional study analyzing clinical characteristics and impact or risk factors among T2DM patients with standard protocol (metformin and SU), as well as the most commonly used treatment regimens.

Most patients (> 25\%) were prescribed sulfonylureas add on to first-line metformin. This result matched to a population-based study that assessed which class of drugs was most commonly prescribed as second-line treatment added to metformin in the period between 2011 and 2015 where the results showed that these drugs are sulfonylureas [23]. Similarly, the study of Zekarias et al. [24] found that more than $50 \%$ of patients were prescribed sulfonylureas.

When comparing male and female sexes between each protocol, we found that almost all protocols 


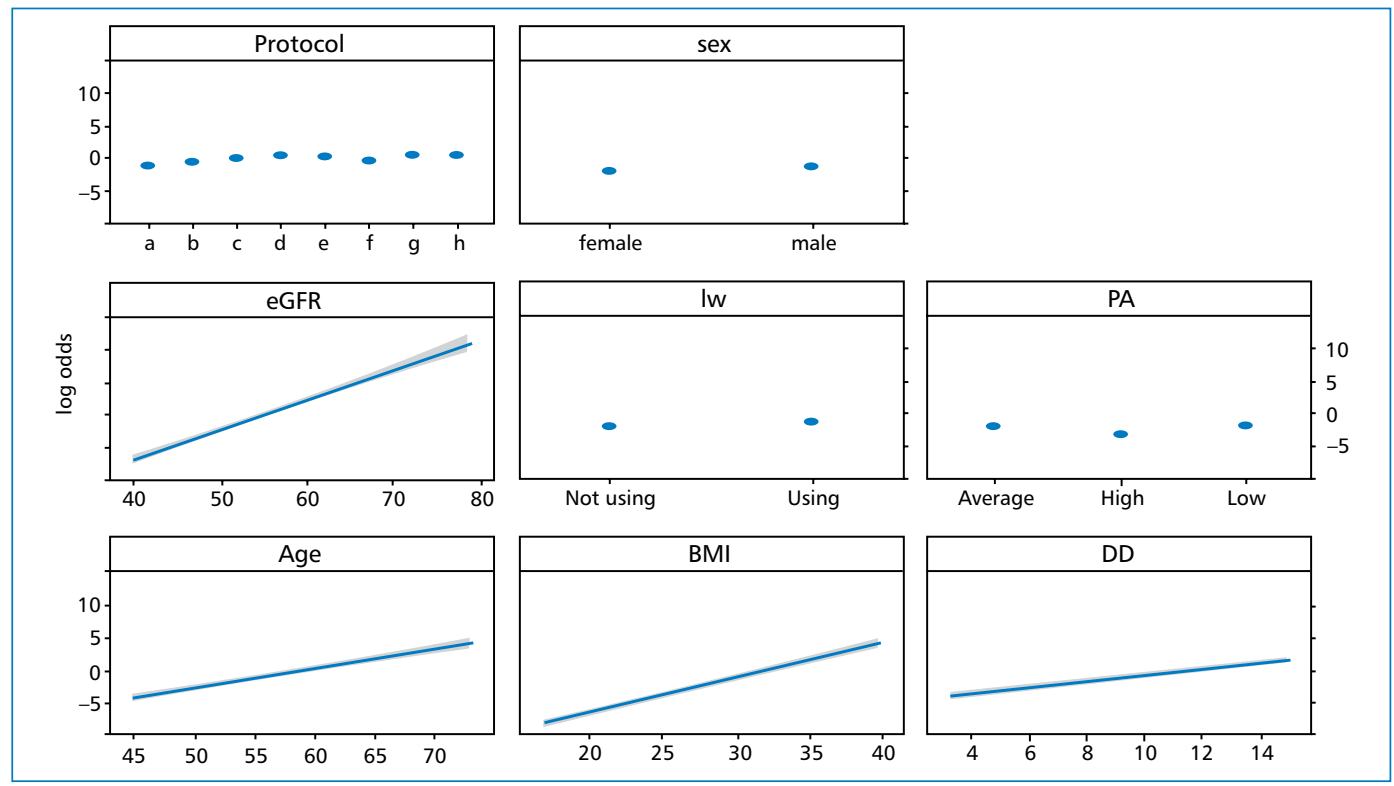

Figure 2. Change in log (odds ratio) by changing each independent variable. Lw - lipid-lowering medication; PA - physical activity; DD - disease duration; BMI - body mass index; eGFR - estimated glomerular filtration rate

Table 4. Multivariate regression for significant variables and each protocol to estimate likelihood [(OR) with $95 \% \mathrm{Cl}]$ of having $\mathrm{HbA}_{1 \mathrm{c}}>7 \%$

\begin{tabular}{|c|c|c|c|c|c|c|}
\hline \multirow[t]{2}{*}{ Clinical variable } & \multicolumn{3}{|c|}{ Univariate analysis } & \multicolumn{3}{|c|}{ Multivariate analysis } \\
\hline & Regression coefficient & SE & $P$ value & Adjusted OR & $95 \% \mathrm{Cl}$ & $P$ value \\
\hline Age (years) & 0.133 & 0.008 & $<0.001$ & 1.35 & $1.29-1.41$ & $<0.0001(\mathrm{~S})$ \\
\hline BMI $\left[\mathrm{kg} / \mathrm{m}^{2}\right]$ & 0.178 & 0.012 & $<0.001$ & 1.71 & $1.61-1.82$ & $<0.0001(\mathrm{~S})$ \\
\hline eGFR $[\mathrm{mL} / \mathrm{min}]$ & 0.173 & 0.009 & $<0.001$ & 1.58 & $1.5-1.65$ & $<0.0001(\mathrm{~S})$ \\
\hline \multicolumn{7}{|l|}{ Protocol } \\
\hline B & -0.104 & 0.15 & 0.49 & 1.71 & $0.94-3.12$ & 0.081 (NS) \\
\hline C & 0.205 & 0.17 & 0.22 & 3.92 & $1.96-7.81$ & $0.0001(S)$ \\
\hline D & 0.266 & 0.17 & 0.12 & 5.18 & $2.52-10.66$ & $<0.0001(\mathrm{~S})$ \\
\hline $\mathrm{E}$ & 0.124 & 0.16 & 0.45 & 4.41 & $2.17-8.96$ & $<0.0001(\mathrm{~S})$ \\
\hline $\mathrm{F}$ & -0.03 & 0.17 & 0.86 & 2.89 & $1.41-5.92$ & $0.0038(\mathrm{~S})$ \\
\hline G & 0.195 & 0.16 & 0.22 & 5.8 & $2.91-11.54$ & $<0.0001(\mathrm{~S})$ \\
\hline $\mathrm{H}$ & 0.312 & 0.176 & 0.08 & 5.22 & $2.58-10.56$ & $<0.0001(\mathrm{~S})$ \\
\hline Sex & 0.34 & 0.093 & $<0.0001$ & 2.23 & $1.58-3.17$ & $<0.0001(\mathrm{~S})$ \\
\hline \multicolumn{7}{|l|}{ PA level } \\
\hline High (PA) & -0.32 & 0.13 & 0.013 & 0.37 & $0.23-0.6$ & $<0.0001(\mathrm{~S})$ \\
\hline Low (PA) & 0.23 & 0.1 & 0.028 & 1.93 & $1.32-2.83$ & $0.0007(\mathrm{~S})$ \\
\hline Disease duration (years) & 0.24 & 0.021 & $<0.0001$ & 1.6 & $1.42-1.8$ & $<0.0001(\mathrm{~S})$ \\
\hline Lipid-lowering agent use & 0.0021 & 0.092 & 0.98 & 0.58 & $0.41-0.81$ & $0.0016(S)$ \\
\hline
\end{tabular}

$\mathrm{OR}$ - odd ratio; $\mathrm{Cl}$ - confidence interval; $\mathrm{HbA}_{1 \mathrm{c}}$ - hemoglobin $\mathrm{A} 1 \mathrm{c}$; eGFR — estimated glomerular filtration rate; $\mathrm{BMI}$ - body mass index; $\mathrm{PA}$ - physical activity

showed marginally higher proportions of men reaching $\mathrm{HbA}_{1 \mathrm{c}} \leq 7 \%$, unlike a study of Ekström et al. [25] that found a proportion of women marginally higher with non-pharmacological treatment and metformin monotherapy. And there was a higher proportion of men reaching treatment goal on metformin + premixed analogues containing rapid-acting insulin and metformin + SU only. However, these differences were no statistically significant, except in only two protocols (metformin and SU) and (metformin and DPP-4 inhibi- 


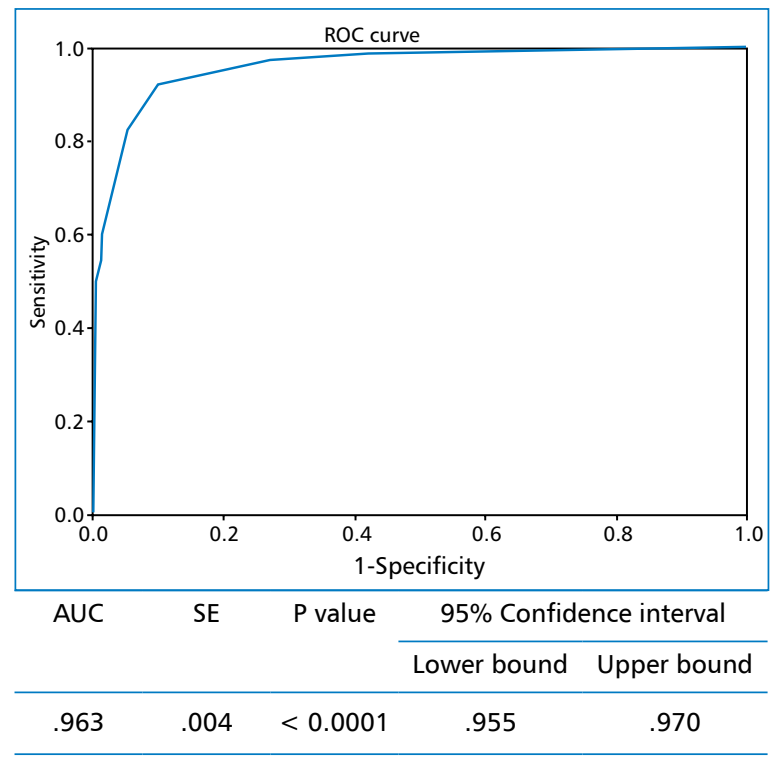

Figure 3. ROC curve of the final multivariate model

tors). Thus, the clinical significance of these minor differences is controversial.

In GRADE study [26] on 5000 patients categorized on the following medications: sulfonylureas, dipeptidyl peptidase 4 inhibitors, glucagon-like peptide 1 receptor agonists, and insulin as the second-line added to metformin found $64 \%$ of all participants reporting statin use but in our study, $58 \%$ of all participants reported statin use although new guidelines recommend statin for all patients with diabetes who are $>40$ years of age, although without other cardiovascular risk. Unfortunately, this percent indicates poor compliance with the guidelines [27].

According to ADA and the European Association for the Study of Diabetes, guidelines recommend starting basal insulin when $\mathrm{HbA}_{1 \mathrm{c}}$ is $>9 \%$ [22]. Our findings from real practice does not support this recommendation, as there is high percent of patients with baseline $\mathrm{HbA}_{1 c}>9$ treated effectively with metformin and sulfonylurea protocol and metformin and DPP-4 inhibitors protocols; this finding is similar to that of Wilding et al. [28]. This result may not be consistent with guidelines because a high proportion of patient have $\mathrm{HbA}_{1 c}>9$ not because of treatment resistance but due to poor adherence to treatment regimen. On other hand, mean reduction in $\mathrm{HbA}_{1 \mathrm{c}}$ from baseline for those on metformin and sulfonylurea was significantly larger than all other protocols, so we conclude that treatment options for those with $\mathrm{HbA}_{1 c}>9 \%$ might not need to be limited only to insulin.

In comparison to study of Ekström et al. [25], insulin-based protocol achieved a higher proportion of patient $\mathrm{HbA}_{1 \mathrm{c}} \leq 7 \%$, as clinician in Egypt use insulin as add on to metformin early in management. So, patient respond better than those who start insulin late. Also percent of patients achieving target LDL was significantly lower in our study, but our result matched with Ekström et al. [29], ADA, IDF and AACE guidelines that patient with metformin protocol had less history of CVD, microalbuminuria and percent of people achieving blood pressure goals as all groups ranged from $41.2-49.3 \%$.

Yurgin et al. [30] found on German patients that around $50 \%$ of patients did not achieve target $\mathrm{HbA}_{1 \mathrm{c}}$ $<6.5$. However, this ratio is not applicable in our study as we reached in some protocols more than $55 \%$ (metformin + SU, metformin + DPP-4 inhibitors and metformin + SU + insulin NPH. Although German study included higher number of participant, our study addressed risk factors and patient characteristics not studied in German study, such as diabetes duration, blood pressure, eGFR, LDL and body mass index.

According to ADA and EASD, Swedish and international guidelines based on trials [31, 32], metformin is the first-line treatment when lifestyle and nonpharmacological interventions are insufficient, and also a higher proportion of patient is treated with metformin monotherapy or in combination, so our real practice is consistent with this guidelines. But there are fewer studies which compare between different protocols and determine which protocol has the likelihood that patient achieve or not achieve the target; therefore, we in Table 4 found that only one protocol (metformin and DPP-4 inhibitors) was nonsignificant with standard protocol (metformin and SU) in likelihood of patient reaching $\mathrm{HbA}_{1 \mathrm{c}}>7$ and all other protocols are significant and odd ratio of patient reaching $\mathrm{HbA}_{1 \mathrm{c}}>7$ ranges from 2.89-5.8. So, we strongly recommend metformin + SU and metformin + DPP-4 inhibitors protocols, but we did not address cost, consequences, CVD exacerbation, and incidence of hypoglycemia of these protocols to make a complete judgment.

This study discusses the determinants of adequate glycemic control in T2DM population, explaining their underlying relative weights, and how they may affect the clinical decision regarding the choice of the antihyperglycemic protocol on an individual basis. The main strength point in the current study is comparative analysis of eight different and commonly used protocols in patients with diabetes as we study the effect of significant variables and how each variable, such as age, BMI, sex, physical activity, disease duration, lipidlowering agents and eGFR, can predict the outcome (Figs 1, 2). Thus, we conclude that good outcome does not dependent only on which protocol patient will be 
treated but also these variables must be evaluated first and monitored.

The major strengths of this observational study are that patients were treated at hospital outpatient clinics nation-wide, representing the real-life situation in clinical practice; also $\mathrm{HbA}_{1 \mathrm{c}}$ analyses were quality assured.

\section{Conclusion}

The likelihood of reaching $\mathrm{HbA}_{1 \mathrm{c}}>7$ is lower in the protocol $A$ and protocol $B$, and other protocols are associated with a significantly higher likelihood of reaching target $\mathrm{HbA}_{1 \mathrm{c}}$ in comparison to protocol A. Significant variables, age, BMI, sex, physical activity, disease duration, lipid-lowering agents and eGFR if controlled, can improve treatment outcome significantly.

\section{Study limitations}

There are also some limitations. Data from participating outpatient clinics may vary slightly in accuracy, although increased use of electronic dataset for data transfer can mitigate this problem. Also, around 20\% of patients were excluded because of missing data. Controlling diet in this number of participants in each group is difficult and may cause slight changes in the response of each group to their medication. Blood lipid values were not measured at baseline. Instead, we used lipid-lowering medication (mostly statins) as a marker of the presence of dyslipidemia. Information regarding doses of drugs in protocols was not available, but the aim was to analyze the effect of clinical characteristics and risk factors on treatment outcome of each protocol with simulating in real practice.

\section{Recommendations}

Large, multicenter, observational studies in similar patient populations are needed to validate our conclusion.

\section{Compliance with ethical standards}

Informed consent was obtained from each patient included in the study, and the study protocol was conducted in compliance with the 1975 Declaration of Helsinki and approved by Faculty of Pharmacy, Helwan University Ethical Committee.

\section{Conflicts of interest}

None of the authors have a conflict of interest.

\section{REFERENCES}

1. Afshin A, Forouzanfar MH, Reitsma MB, et al. GBD 2015 Obesity Collaborators. Health Effects of Overweight and Obesity in 195 Countries over 25 Years. N Engl J Med. 2017; 377(1): 13-27, doi: 10.1056/NEJMoa1614362, indexed in Pubmed: 28604169.

2. Menke A, Casagrande S, Geiss L, et al. Prevalence of and Trends in Diabetes Among Adults in the United States, 1988-2012. JAMA.
2015; 314(10): 1021-1029, doi: 10.1001/jama.2015.10029, indexed in Pubmed: 26348752.

3. International Diabetes Federation (2017) IDF Atlas 8th edition. International Diabetes Federation, Brussels. http://www.diabe tesatlas.org (26.11.2019).

4. Park J, Peters PA. Mortality from diabetes mellitus, 2004-2008: a multiple-causeof-death analysis. Health Rep. 2014; 25(3): 12-16.

5. Preis SR, Hwang SJ, Coady S, et al. Trends in all-cause and cardiovascular disease mortality among women and men with and without diabetes mellitus in the Framingham Heart Study, 1950 to 2005 . Circulation. 2009; 119(13): 1728-1735, doi: 10.1161/ CIRCULATIONAHA.108.829176, indexed in Pubmed: 19307472.

6. Pugliese G, Solini A, Bonora E, et al. RIACE Study Group. Chronic kidney disease in type 2 diabetes: lessons from the Renal Insufficiency And Cardiovascular Events (RIACE) Italian Multicentre Study. Nutr Metab Cardiovasc Dis. 2014; 24(8): 815-822, doi: 10.1016/j.numecd.2014.02.013, indexed in Pubmed: 24780515.

7. Rao C, Adair T, Bain C, et al. Mortality from diabetic renal disease: a hidden epidemic. Eur J Public Health. 2012; 22(2): 280-284, doi: 10.1093/eurpub/ckq205, indexed in Pubmed: 21245077.

8. Coresh J, Selvin E, Stevens LA, et al. Prevalence of chronic kidney disease in the United States. JAMA. 2007; 298(17): 2038-2047, doi: 10.1001/jama.298.17.2038, indexed in Pubmed: 17986697 7. Bunce C, Wormald R (2008) Causes of blind certifcations in England and Wales: April 1999-March 2000. Eye. 2007; 22(7):905-9118.

9. Vamos EP, Bottle A, Edmonds ME, et al. Changes in the incidence of lower extremity amputations in individuals with and without diabetes in England between 2004 and 2008. Diabetes Care. 2010; 33(12): 2592-2597, doi: 10.2337/dc10-0989, indexed in Pubmed: 20833865.

10. Jansson SPO, Andersson DKG, Svärdsudd K. Mortality trends in subjects with and without diabetes during 33 years of follow-up. Diabetes Care. 2010; 33(3): 551-556, doi: 10.2337/dc09-0680, indexed in Pubmed: 20009100.

11. American Diabetes Association (2019) Standards of medical care in Diabetes. Diabetes Care. 2019; 42(13): 28.

12. Orozco-Beltrán D, Gil-Guillen VF, Quirce $F$, et al. Collaborative Diabetes Study Investigators. Control of diabetes and cardiovascular risk factors in patients with type 2 diabetes in primary care. The gap between guidelines and reality in Spain. Int J Clin Pract. 2007; 61(6): 909-915, doi: 10.1111/j.1742-1241.2007.01367.x, indexed in Pubmed: 17504353.

13. Hermans MP, Brotons $C$, Elisaf M, et al. (for the OPTIMISE (OPtimal Type 2 dlabetes Management Including benchmarking and Standard trEatment) International Steering Committee). Optimal type 2 diabetes mellitus management: the randomised controlled OPTIMISE benchmarking study: baseline results from six European countries. Eur J Prev Cardiol. 2013; 20(6): 1095-1105, doi: 10.1177/2047487312449414, indexed in Pubmed: 22605788.

14. Standards of Medical Care in Diabetes-2016: Summary of Revisions. Diabetes Care. 2016; 39 Suppl 1: S4-S5, doi: 10.2337/ dc16-S003, indexed in Pubmed: 26696680.

15. Holman RR, Paul SK, Bethel MA, et al. 10-year follow-up of intensive glucose control in type 2 diabetes. N Engl J Med. 2008; 359(15): 1577-1589, doi: 10.1056/NEJMoa0806470, indexed in Pubmed: 18784090.

16. Maruthur NM, Tseng E, Hutfless S, et al. Diabetes medications as monotherapy or metformin-based combination therapy for type 2 diabetes: a systematic review and meta-analysis. Ann Intern Med. 2016; 164(11): 740-751, doi: 10.7326/M15-2650, indexed in Pubmed: 27088241.

17. Bennett WL, Maruthur NM, Singh S, et al. Comparative effectiveness and safety of medications for type 2 diabetes: an update including new drugs and 2-drug combinations. Ann Intern Med. 2011; 154(9): 602-613, doi: 10.7326/0003-4819-154-9201105030-00336, indexed in Pubmed: 21403054.

18. Vijan S, Sussman JB, Yudkin JS, et al. Effect of patients' risks and preferences on health gains with plasma glucose level lowering in type 2 diabetes mellitus. JAMA Intern Med. 2014; 174(8): 
1227-1234, doi: 10.1001/jamainternmed.2014.2894, indexed in Pubmed: 24979148.

19. Ford ES. Trends in the control of risk factors for cardiovascular disease among adults with diagnosed diabetes: findings from the National Health and Nutrition Examination Survey 19992008*. J Diabetes. 2011; 3(4): 337-347, doi: 10.1111/j.17530407.2011.00148.x, indexed in Pubmed: 21767347.

20. Levey AS, Bosch JP, Lewis JB, et al. A more accurate method to estimate glomerular filtration rate from serum creatinine: a new prediction equation. Modification of Diet in Renal Disease Study Group. Ann Intern Med. 1999; 130(6): 461-470, doi: 10.7326/0003-4819-130-6-199903160-00002, indexed in Pubmed: 10075613.

21. Ainsworth BE, Haskell WL, Leon AS, et al. Compendium of physical activities: classification of energy costs of human physical activities. Med Sci Sports Exerc. 1993; 25(1): 71-80, doi: 10.1249/00005768-199301000-00011, indexed in Pubmed: 8292105.

22. Srivastava A. Bringing ADA 2019 and EASD 2018 Guidelines in Clinical Practice. Int J Diab. 2019; 22: 29

23. Ackermann RT, Wallia A, O'Brien MJ. Correlates of second-line type 2 diabetes medication selection in the USA. BMJ Open Diabetes Res Care. 2017; 5: e000421.

24. Zekarias K, Davey C, Seaquist E. Intensification of medical management in type 2 diabetes: A real-world look at primary care practice. J Diabetes Complications. 2020; 34(1): 107477, doi: 10.1016/j.jdiacomp.2019.107477, indexed in Pubmed: 31711841.

25. Ekström N, Miftaraj M, Svensson AM, et al. Glucose-lowering treatment and clinical results in 163121 patients with type 2 diabetes: an observational study from the Swedish national diabetes register. Diabetes Obes Metab. 2012; 14(8): 717-726, doi: 10.1111/j.1463-1326.2012.01591.x, indexed in Pubmed: 22364580 .
26. Nathan DM, Buse JB, Davidson MB. Medical management of hyperglycemia in type 2 diabetes: a consensus algorithm for the initiation and adjustment of therapy: a consensus statement of the American Diabetes Association and the European Association for the Study of Diabetes. Diabetes Care. 2009; 32(193): 203.

27. Chamberlain JJ, Herman WH, Leal S, et al. Pharmacologic Therapy for Type 2 Diabetes: Synopsis of the 2017 American Diabetes Association Standards of Medical Care in Diabetes. Ann Intern Med. 2017; 166(8): 572-578, doi: 10.7326/M16-2937, indexed in Pubmed: 28288484.

28. Wilding J, Godec T, Khunti K. Changes in HbA1c and weight, and treatment persistence, over the 18 months following initiation of second-line therapy in patients with type 2 diabetes: results from the United Kingdom. Clinical Practice Research Datalink BMC Med. 2018; 16: 116.

29. Handelsman Y, Mechanick JI, Blonde L, et al. AACE Task Force for Developing Diabetes Comprehensive Care Plan. American Association of Clinical Endocrinologists Medical Guidelines for Clinical Practice for developing a diabetes mellitus comprehensive care plan. Endocr Pract. 2011; 17 Suppl 2: 1-53, doi: 10.4158/ep.17. s2.1, indexed in Pubmed: 21474420.

30. Yurgin N, Secnik K, Lage MJ. Antidiabetic prescriptions and glycemic control in German patients with type 2 diabetes mellitus: a retrospective database study. Clin Ther. 2007; 29(2): 316-325, doi: 10.1016/j.clinthera.2007.02.012, indexed in Pubmed: 17472823.

31. Effect of intensive blood-glucose control with metformin on complications in overweight patients with type 2 diabetes (UKPDS 34). The Lancet. 1998; 352(9131): 854-865, doi: 10.1016/ s0140-6736(98)07037-8.

32. Bolen SD, Bricker E, Samuels TA, et al. Factors associated with intensification of oral diabetes medications in primary care provider-patient dyads: a cohort study. Diabetes Care. 2009; 32(1): 25-31, doi: 10.2337/dc08-1297, indexed in Pubmed: 18931096. 